\title{
A CLINICOPATHOLOGICAL STUDY OF OROFACIAL SWELLINGS (A PROSPECTIVE STUDY)
}

\author{
Sarah R. Taher ${ }^{l}$, Nagy E. Hassan², Sahar M. El Sheikh³, Riham M. El Dibany ${ }^{2}$
}

\begin{abstract} divided into benign and malignant types. and type of lesion. Statistical analysis was carried out on the tabulated data using (IBM SPSS 20.0) software. and $6 \%$ as salivary gland tumors. the entire surgical specimen should be examined histopathologically.

1- Bachelor of Dentistry, BDS, Faculty of Dentistry, Alexandria University, Alexandria, Egypt.

2- Professor of Oral and Maxillofacial surgery, Faculty of Dentistry, Alexandria University, Egypt.

3- Professor of Oral Pathology, Faculty of Dentistry, Alexandria University, Egypt.
\end{abstract}

INTRODUCTION: The etiology of orofacial swellings could be attributed to the presence of inflammation, congenital developmental malformations and neoplasia. Orofacial swellings may occur in the nasal cavities, paranasal sinuses, ear, eye, facial skin, oral cavity and salivary glands. Swellings of the orofacial region include cysts and tumors. Cysts are divided into developmental and inflammatory types. Tumors are

OBJECTIVES: Perform clinicopathological correlation of orofacial swellings and assess the frequency of incidence regarding age, sex, site,

MATERIALS AND METHODS: A clinicopathological prospective study was conducted on 100 patients suffering from swellings in the orofacial region attending the outpatient clinic of the oral and maxillofacial surgery department. The histopathological examination was done.

RESULTS: It was found that the incidence of all swellings in males was slightly more than females. The incidence of all swellings in the second and third decades of age. The mandible was the most frequently affected site. Using the histological classification of the World Health Organization (WHO), 32\% were classified as cysts, $26 \%$ as odontogenic tumors, $25 \%$ as non-odontogenic tumors, $11 \%$ fibro-osseous lesions

CONCLUSIONS: Cysts are the most common oral swellings, followed by odontogenic tumors. The treatment modalities were: marsupialization, enucleation, resection, segmental mandibulectomy and hemimandibulectomy. Following surgical removal of jaw swelling,

KEYWORDS: Cysts, Odontogenic tumors, Non-odontogenic tumors, Fibro-osseous lesions, Salivary gland tumors.

\section{INTRODUCTION}

The risk factors of orofacial pathology include genetic susceptibility, tobacco and alcohol use, ultra violet light exposure, occupational exposures, radiation exposure, nutritional deficiency and low socioeconomic condition (related to poor hygiene), and human papilloma virus (HPV) infection (1-3).

The types of jaw cysts according to diagnosis are: radicular cysts $(\mathrm{RC})$, dentigerous cysts (DC), nasopalatine duct cysts (NPDC), odontogenic keratocysts (OKC), globulomaxillary cysts, traumatic bone cysts (TBC), and eruption cysts (EC). According to the 2005 WHO Classification of tumors, $\mathrm{OKC}$ is currently designated as a keratocystic odontogenic tumor (KCOT) and is defined as a benign unicystic or multicystic, intraosseous odontogenic tumor. KCOT has a characteristic lining of parakeratinized stratified squamous epithelium with an aggressive, infiltrative behavior. Although they are benign, KCOT are locally aggressive and have a tendency to recur after treatment. The orthokeratotic type, which is now recognized as an entirely separate lesion, is represented by the terminology, orthokeratinzed odontogenic cyst (OOC) thus requiring a more conservative surgical treatment. Recently OKC had been returned to the Cystic classification. (4).

Tumors or neoplasms are abnormal growth of the tissue in the body. They are basically divided into two separate entities; benign and malignant. Benign jaw tumors are divided into three categories: odontogenic, nonodontogenic and salivary gland tumors. Benign odontogenic tumors are neoplasms that arise from residues of the dental apparatus such as epithelial rests of Serres, epithelial rests of Malassez and dental lamina (5).

Odontogenic tumors are normally classified by their presumed tissue of origin, being epithelial, mesenchymal, or a mixed lesion according to WHO such as ameloblastoma, calcifying epithelial odontogenic tumor (pindborg tumor), adenomatoid odontogenic tumor and others (6).

Ameloblastoma is a benign odontogenic tumor located exclusively in the jaws; it is a locally-invasive epithelial tumor with tendency to recur. Ameloblastoma is usually unicentric, intermittent in growth, anatomically-benign and clinically-persistant. They are divided into three types such as conventional solid ameloblastomas, unicystic ameloblastomas and peripheral ameloblastomas. Malignant ameloblastoma metastasize as well differentiated benign cells. Metastases are most common to regional lymph nodes, but also are seen frequently in the lung, and virtually any organ may be affected by metastasis. Ameloblastic carcinoma reveals malignant histopathological features independent of the presence of metastasis (6).

Squamous cell carcinoma (SCC) is the most common head and neck malignant tumor. Squamous cell carcinoma most commonly occurs on the lip, floor or roof of the mouth, tongue, soft palate and gingiva (7). It spreads chiefly by direct invasion and by lymphatic permeation but also by blood vessel embolism. Basal cell carcinoma (BCC) and verrucous carcinoma (VC) are variants of squamous cell carcinoma (8).

Salivary gland tumors consist of a group of heterogeneous lesions with complex clinicopathological characteristics and distinct biological behaviors. Parotid gland tumors are the most 
frequent. The most frequent tumors are pleomorphic adenomas. Benign tumors are significantly more frequent in the parotid, while malignant tumors are more frequent in the minor salivary glands. Females are more affected than males. Pleomorphic adenoma is the most frequent lesion, followed by adenoid cystic carcinoma and warthin's tumor (9).

Treatment of cysts and tumors of the orofacial region are determined by the etiology of the mass. Two techniques can be used in clinical practice for the treatment of cysts: enucleation and decompression (10). Benign masses are usually removed by surgical excision, En bloc resection, hemimandibulectomy, or partial maxillectomy, depending on their size. Head and neck cancers are treated by combination of surgery followed by radiation therapy and chemotherapy depending on their nature (11).

The purpose of this study was to perform clinicopathological correlation of orofacial swellings and to assess the frequency of incidence regarding age, sex, different sites, and type of lesion.

\section{MATERIALS AND METHODS}

\section{Selection of patients}

This study was conducted on 100 patients suffering from swellings in the orofacial region and attending the Outpatient Clinic of the Oral and Maxillofacial Surgery Department, Faculty of Dentistry, Alexandria University. The histopathological study was conducted in the Oral Pathology Department, Faculty of Dentistry, Alexandria University.

All patients suffering from orofacial swellings were included in this study. Patients suffering from inflammatory swellings such as abscess, granuloma and cellulitis or post traumatic swelling were excluded from the study.

\section{Methods}

\section{A) Pre-operative phase \\ - Clinical examination}

All clinical data and relevant history were collected from patients. This data included:

1. Demographic characteristics of the patients (name, age, and sex).

2. Chief complaint of the patient.

Clinical picture of the swelling and physical examination were carried out by careful inspection and palpation of the soft and hard tissues. Intra and Extra-oral examination was carried out to detect the anatomic location, size and shape of the lesion, consistency, surface and color of overlying tissue, fluctuation, single or multiple lesions and lymph node examination.

\section{Radiographic examination}

Depending upon the origin and location of the lesion, radiograghic examination was performed; plain film radiography, panoramic, periapical, occlusal views or any other necessary view. Some of them were referred to undergo computed tomography (CT) or magnetic resonance imaging (MRI).

\section{Laboratory investigations}

Blood analysis and laboratory investigations in the form of complete blood count, liver functions, kidney functions, serum calcium, phosphorus, phosphate, alkaline phosphatase serum levels, parathyroid hormone or any other hormone that could be related to a systemic disease. These were performed according to the characteristics and differential diagnosis of the lesion.

\section{Aspiration biopsy}

- Aspiration biopsy using a needle and syringe to penetrate a lesion for aspiration of its contents.

- An 18-gauge needle on a 5 or $10 \mathrm{ml}$ syringe was inserted into the area under investigation after anesthesia was obtained.

The syringe was aspirated and the needle redirected if necessary to find the fluid cavity.

\section{B) Operative phase}

Depending on the case, surgery was performed under local or general anesthesia and it included one of the following treatment modalities: Incisional or excisional biopsy. Incisional Biopsy is preferred especially for larger lesions prior to definitive therapy and excisional biopsies are preferred for smaller unilocular tumors. Marsupialization, enucleation, resection, segmental mandibulectomy or hemimandibulectomy were also performed.

The choice of the type of biopsy performed depends on various factors relating to the lesion, such as: site, size, relations with surrounding tissues, type of surrounding tissue and suspected diagnosis.

A biopsy technique can be reduced to five steps: preparation of the surgical field, local anaesthesia, incision, handling of the specimen and suturing of the resulting wound.

\section{Excisional Biopsy}

It was performed in cases of clinically benign lesions of diameter less than or equal to $2 \mathrm{~cm}$, in case of pedunculated lesions, clinically malignant lesions of diameter less than $1 \mathrm{~cm}$, or clinically benign lesions larger than $2 \mathrm{~cm}$ located in areas of particular aesthetic or functional importance. It is better to excise it for examination of the whole lesion histopathologically.

Incisional Biopsy

It was performed in cases of malignant or suspected lesions larger than $1 \mathrm{~cm}$ or in areas of particular aesthetic or functional importance, it was better to make sure of the true nature of the lesion, before proceeding to the complete removal of the same lesion.

Two techniques were used in clinical practice for surgical removal of cysts: enucleation and masupialization

\section{Enucleation}

Enucleation is the treatment of choice for removal of cysts of the jaws that can be safely removed without sacrificing adjacent structure. A clean and defined incision was performed, reflection of a mucoperiosteal flap, followed by removal of bone and exposure of the cyst membrane was carried out. The cyst was totally curetted to the maximum extent. Then bone filing and irrigation with sterile saline were performed. Enucleation of the cystic lesion and extraction or apicectomy of the affected teeth with care of the wound. The flap was replaced and suturing was done.

\section{Marsupialization}

Marsupialization of the lesion was done under local or general anaesthesia. The superficial cyst lining was enucleated and the cystic contents were removed. The lining of the cyst was sutured to the surrounding oral mucosa. The cavity was irrigated with normal saline, and then packed with iodoform gauze. The dressing was changed every alternate day for a week and then an obturator was fabricated into a partial denture treatment and placed over the defect to guide the bone healing, also to prevent food accumulation and maintain a patent surgical opening. The patient was trained to maintain oral hygiene and was reviewed periodically. 


\section{Other treatment modalities \\ Resection}

Surgical removal of the entire tumor; also known as en bloc resection. This method was used in cases of aggressive tumors to prevent tumor recurrence.

\section{Segmental mandibulectomy}

The resected specimen included the lesion and $1 \mathrm{~cm}$ bony margins around the radiographic boundaries of the lesion.

\section{C) Post-operative phase}

- Postoperative instructions were given to the patients including cold packs on the first day postoperatively, then hot fomentation for the second day.

- Postoperative medications including:

1- Antibiotics: Amoxicillin $875 \mathrm{mg}$, Clavulanic acid $125 \mathrm{mg}$ (Augmentin 1gm, Smithline Beecham Pharmaceutical Co., Bentford, England) tablets twice daily for 5 days to avoid postoperative infection.

2-Non-steroidal anti-inflammatory analgesics in the form of diclofenac potassium (Cataflam 50mg tablets, Novartis Pharma AG,Basle, Switzerland) (50mg tablets 3 times daily for 3 days depends on the severity of the procedure) to avoid the possibility of inflammation, oedema and pain.

3-Chlorohexidine HCL $0.12 \%$ (Hexitol mouth wash, the Arab Drug Co., Cairo, Egypt) mouth wash twice daily from the second post-operative day after surgery to the seventh day.

- Sutures were removed after 7-10 postoperative day.

\section{D) Histopathological phase}

Biopsies were studied histopathologically to confirm the diagnosis. Biopsies were taken from the swelling tissue, fixed in $10 \%$ neutral buffered formalin (PH 7.0) then processed and embedded in paraffin wax using conventional procedures. Serial sections of $5 \mu \mathrm{m}$ thick were cut from formalin fixed, paraffin embedded tissue blocks, placed on glass slides and stained using hematoxylin and eosin $(\mathrm{H} \& \mathrm{E})$, for routine histopathological examination.

\section{E) Statistical analysis of the data}

Data were fed to the computer and analyzed using IBM SPSS software package version 20.0. Qualitative data were described using number and percent. Significance of the obtained results was judged at the $5 \%$ level.

The used tests were

\section{1 - Chi-square test}

For categorical variables, to compare between different groups.

\section{2 - Fisher's Exact or Monte Carlo correction}

Correction for chi-square when more than $20 \%$ of the cells have expected count less than 5 .

\section{Informed consent}

Appropriate institutional ethical clearance and written informed consents were obtained from all patients.

\section{RESULTS}

In the current survey, 100 patients were included in the study and studied through the year 2014 from the Outpatient Clinic of Oral and Maxillofacial Surgery Department, Faculty of Dentistry, Alexandria University. The histopathological study was conducted in the Oral Pathology Department, Faculty of Dentistry, Alexandria University.

\section{Demographic data}

Fifty-one percent of the total patients were males and $49 \%$ of the total patients were females in the current study. (Table 1)

The patients' age in the current study ranged between two days and 75 years. They were divided into four age groups. Group one ( 2 days -15 years), this age group represented 19\% from the studied patients (10 females - 9 males). Group two (16-35 years), this age group represented $43 \%$ from the studied patients (21 females - 22 males). Group three (36-55 years), this age group represented $22 \%$ from the studied patients (12 females 10 males). Group four (56-75 years), this age group represented $16 \%$ from the studied patients ( 6 females -10 males). (Table 1$)$

Table 1: Demographic distribution of the studied cases.

\begin{tabular}{|c|c|c|c|c|c|}
\hline $\begin{array}{c}\text { Sex } \\
\text { Age } \\
\text { group }\end{array}$ & $\begin{array}{c}\text { Group } \\
\mathbf{1} \text { days } \\
\text { to 15 } \\
\text { years }\end{array}$ & $\begin{array}{c}\text { Group } \\
\text { (2) } \\
\mathbf{1 6} \text { to 35 } \\
\text { years }\end{array}$ & $\begin{array}{c}\text { Group } \\
\mathbf{( 3 )} \\
\mathbf{3 6} \text { to 55 } \\
\text { years }\end{array}$ & $\begin{array}{c}\text { Group(4) } \\
\mathbf{5 6} \text { to 75 } \\
\text { years }\end{array}$ & Total \\
\hline Males & 9 & 22 & 10 & 10 & 51 \\
\hline Females & 10 & 21 & 12 & 6 & 49 \\
\hline Total & 19 & 43 & 22 & 16 & 100 \\
\hline
\end{tabular}

\section{Pre-operative clinical examination}

The anatomical distribution of the studied cases showed that the most common site of occurrence was the mandible $42 \%$, followed by the maxilla $34 \%$, the cheek $11 \%$, the lower lip $6 \%$, the tongue $4 \%$, the parotid gland $3 \%$ while the palate was one percent from all the studied patients. (Table 2)

As for the consistency of swellings; $44 \%$ of the swellings were hard, $24 \%$ were firm, $19 \%$ were soft, $10 \%$ had egg shell crackling consistency, while only $3 \%$ were rubbery.

The size of swellings (by measuring the surface area) ranged between $0.5 \mathrm{~mm}^{2}$ and $100 \mathrm{~mm}^{2}$. They were divided into six groups. Group one $\left(0.5-5 \mathrm{~mm}^{2}\right)$ which represented $40 \%$ of all the examined patients. Group two $\left(6-10 \mathrm{~mm}^{2}\right)$ which represented $31 \%$ of all the examined patients. Group three (11 $-15 \mathrm{~mm}^{2}$ ) which represented $12 \%$ of all the examined patients. Group four $\left(16-20 \mathrm{~mm}^{2}\right)$ which represented $5 \%$ of all the examined patients. Group five $\left(21-40 \mathrm{~mm}^{2}\right)$ which represented $7 \%$ of all the examined patients. Group six (41$100 \mathrm{~mm}^{2}$ ) which represented $5 \%$ of all the examined patients.

Regarding the covering overlying mucosa of swellings; $78 \%$ of the swellings were normal, $11 \%$ were red, $7 \%$ were bluish, $3 \%$ were ulcerated, while only $1 \%$ was mixed white and red.

Table 2: Anatomical distribution of the studied cases.

\begin{tabular}{|c|c|}
\hline Location & Percentage \\
\hline Mandible & 42 \\
\hline Maxilla & 34 \\
\hline Cheek & 11 \\
\hline Lip & 6 \\
\hline Tongue & 4 \\
\hline Parotid & 2 \\
\hline Palate & 1 \\
\hline Total & 100 \\
\hline
\end{tabular}

\section{Radiographic examination}

According to the type of $\mathrm{x}$-rays used; 66 cases were orthopanogramic picture film, nine cases were cone beam $\mathrm{CT}$, while only one case was periapical film.

The radiographic appearance of swellings; 60 cases were radiolucent, five cases were radio-opaque and 11 cases had mixed radiolucent radio-opaque appearance.

\section{Operative phase}

Type of anesthesia used; $38 \%$ of the total examined patients were given local anesthesia and $62 \%$ of the patients were given general anesthesia. 
Fine needle aspiration biopsy results; 54 cases out of the total examined patients indicated for aspiration biopsy; 16 cases were straw colored cystic fluid, 15 cases were negative, seven cases were cystic fluid turbid with pus, four cases were cheezy white material, four cases were pus, three cases were clear yellowish fluid, three cases were blood, one case was blood and pus and one case was mucous. (Table 3)

The type of biopsy used; $91 \%$ of the total examined patients underwent excisional biopsy, $9 \%$ of the total examined patients underwent incisional biopsy.

Table 3: Fine needle aspiration biopsy results.

\begin{tabular}{|c|c|}
\hline FNA result & Number of cases \\
\hline Straw colored cystic fluid & 16 \\
\hline Negative & 15 \\
\hline cystic fluid turbid with pus & 7 \\
\hline Cheezy white material & 4 \\
\hline Pus & 4 \\
\hline Clear yellowish fluid & 3 \\
\hline Blood & 3 \\
\hline Blood and pus & 1 \\
\hline Mucous & 1 \\
\hline Total & 54 \\
\hline
\end{tabular}

\section{Diagnosis}

The diagnosis of studied patients; $32 \%$ of the swellings were cysts, $26 \%$ were the odontogenic tumors, $25 \%$ were the non-odontogenic tumors, $11 \%$ were the fibro-osseous lesions while $6 \%$ were the salivary gland tumors. (Figure 1 )



Figure 1: Pie chart representation of the diagnosis of the studied cases.

Cysts

During the survey, $32 \%$ of the total examined cases were cysts. Twenty-two patients $(68.75 \%)$ were males and 10 patients $(31.25 \%)$ were females. There was statistically significant difference between the percentages of males and females diagnosed with cysts. $(\mathrm{P} \leq 0.05)$

Age groups represented as; group one represented nine patients $(28.125 \%)$, group two represented 15 patients $(46.875 \%)$, group three represented seven patients $(21.875 \%)$ and group four represented one patient $(3.125 \%)$. There was no statistically significant difference between the percentages of the age groups diagnosed with cysts. $(\mathrm{P}>0.05)$

The anatomical distribution of the studied cases showed that the most common site of occurrence was the mandible 16 cases $(50.0 \%)$, followed by the maxilla 10 cases $(31.25 \%)$, the lip three cases $(9.375 \%)$, the tongue two cases $(6.25 \%)$ while the cheek one case $(3.125 \%)$ from all the studied patients. There was no statistically significant difference between the percentages of the anatomical location diagnosed with cysts. $(\mathrm{P}>0.05)$

Fifteen cases of radicular cyst which are inflammatory cysts. Six cases of dentigerous cyst which are odontogenic cysts. Six cases of mucocele which are salivary gland cysts. Two cases of traumatic bone cyst, two cases of aneurysmal bone cysts and one case of stafne bone cyst which are nonodontogenic cysts. (Figure 2)



Figure 2: A: Panoramic x-ray showing unilocular radiolucent area surrounded by a radio-opaque halo around the unerupted third molar in the right ramus of mandible. B: Dentigerous cyst showing cystic space lined by thin non-keratinized odontogenic stratified squamous epithelium, mucous cells can be seen within the epithelial lining. (H\&E X 40).

\section{Odontogenic tumors}

The second category was the odontogenic tumors which represented $26 \%$ of all examined patients. Fourteen patients $(53.85 \%)$ were males and 12 patients $(46.15 \%)$ were females. There was no statistically significant difference between the percentages of males and females diagnosed with odontogenic tumors. $(\mathrm{P}>0.05)$

Age groups represented as; group one represented four patients $(15.38 \%)$, group two represented 16 patients (61.54\%), group three represented four patients $(15.38 \%)$ and group four represented two patients $(7.70 \%)$. There was no statistically significant difference between the percentages of the age groups diagnosed with odontogenic tumors. $(\mathrm{P}>0.05)$

The anatomical distribution of the studied cases showed that the most common site of occurrence was the mandible 19 cases $(73.08 \%)$, followed by the maxilla seven cases $(26.92 \%)$. There was statistically significant difference between the percentages of the anatomical location diagnosed with odontogenic tumors. $(\mathrm{P} \leq 0.05)$

Odontogenic tumors compromised $26 \%$ of total studied cases, divided into benign odontogenic tumors (24\%) and malignant odontogenic tumors $(2 \%)$.

Benign odontogenic tumors represented $24 \%$ of the studied cases. There were nine cases of keratocystic odontogenic tumor (KCOT), the eight cases were ameloblastoma; of which five cases were conventional ameloblastoma and three cases were unicystic ameloblastoma. There were two cases of calcifying epithelial odontogenic tumor (CEOT). All the previous tumors are odontogenic epithelial in origin. Concerning the ectomesenchymal tumors. There were two cases of odontogenic fibroma and one case of fibromyxoma. There was one case of complex odontoma and one case of 
ameloblastic fibro-odontoma which are mixed in origin. (Figure 3)

Malignant odontogenic tumors represented 2\%. There were two cases of ameloblastic carcinoma and they are epithelial in origin.

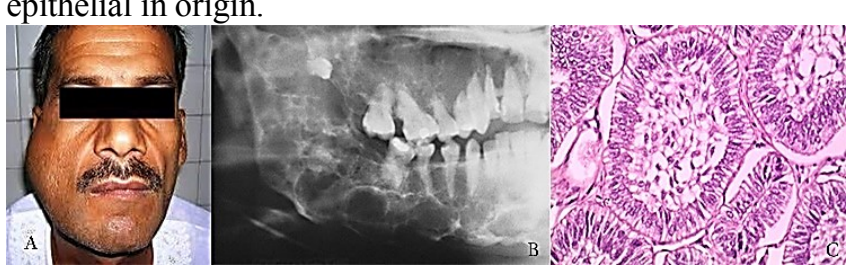

Figure 3: A: clinical view of the patient showing swelling in the right side of mandible. B: panoramic x-ray showing multilocular radiolucent area in the right ramus, angle and body of mandible. C: Follicular ameloblastoma showing peripheral arrangement of ameloblast-like cells with reverse polarity and central located stellate reticulium-like cells. (H\&E X 400)

\section{Non-odontogenic tumors}

Twenty-five percent of cases were non odontogenic tumors. Nine patients $(36 \%)$ were males and 16 patients $(64 \%)$ were females. There was no statistically significant difference between the percentages of males and females diagnosed with non-odontogenic tumors. ( $\mathrm{P}>0.05)$

Age groups represented as; group one represented five patients $(20 \%)$, group two represented six patients $(24 \%)$, group three represented six patients (24\%) and group four represented eight patients (32\%). There was statistically significant difference between the percentages of the age groups diagnosed with non-odontogenic tumors. $(\mathrm{P} \leq 0.05)$

The anatomical distribution of the studied cases showed that the most common site of occurrence was the cheek nine cases $(36 \%)$, followed by the maxilla seven cases $(28 \%)$, the mandible four cases $(16 \%)$, the lip three cases $(12 \%)$, while the tongue two cases $(8 \%)$ from all the studied patients. There was statistically significant difference between the percentages of the anatomical location diagnosed with non-odontogenic tumors. $(\mathrm{P} \leq 0.05)$

Twenty-five percent of patients represented with nonodontogenic tumors. Twenty percent of the examined cases were benign non odontogenic tumors and $5 \%$ of the examined cases were malignant non odontogenic tumors.

Twenty percent of the examined cases were benign non odontogenic tumors. Two cases were squamous cell papilloma which are epithelial in origin. Eleven cases were fibroma. Three cases were fibrolipoma. Two cases were congenital epulis of newborn. One case was lipoma. One case was myxochondroma. All the previous tumors are mesenchymal in origin. (Figure 4)

Five percent of the examined cases were malignant nonodontogenic tumors. Four cases were squamous cell carcinoma and one case of papillary squamous cell carcinoma and they are epithelial in origin.

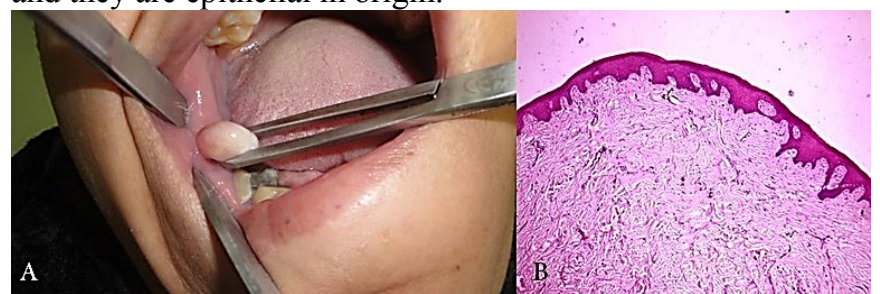

Figure 4: A: clinical view of the patient showing a swelling in the inner aspect of the right cheek. B: Fibroma showing well collagenized fibrous mass covered by keratinized stratified squamous epithelium. (H\&E X 40)

\section{Fibro-osseous lesions}

Eleven percent of the studied cases were fibro-osseous lesions. Four patients $(36.36 \%)$ were males and seven patients $(63.64 \%)$ were females. There was no statistically significant difference between the percentages of males and females diagnosed with fibro-osseous lesions. $(\mathrm{P}>0.05)$

Age groups represented as; group one represented two patients $(18.18 \%)$, group two represented six patients $(54.55 \%)$, group three represented one patient $(9.09 \%)$ and group four represented two patients (18.18\%). There was no statistically significant difference between the percentages of the age groups diagnosed with fibro-osseous lesions. $(\mathrm{P}>0.05)$

The anatomical distribution of the studied cases showed that the most common site of occurrence was the maxilla nine cases $(81.82 \%)$, followed by the mandible two cases $(18.18 \%)$. There was statistically significant difference between the percentages of the anatomical location diagnosed with Fibro-osseous lesions. $(\mathrm{P} \leq 0.05)$

Fibro-osseous lesions made up the fourth category (11\%). Eight cases were ossifying fibroma. Two cases were fibrous dysplasia of bone. One case was juvenile ossifying fibroma. (Figure 5)

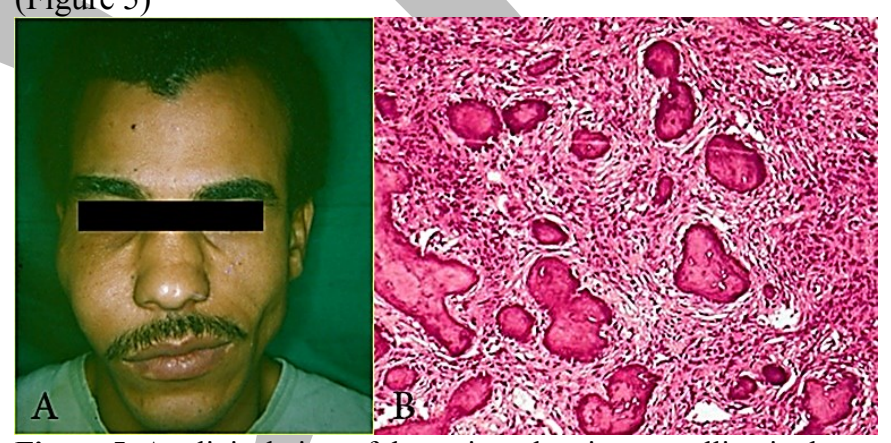

Figure 5: A: clinical view of the patient showing a swelling in the right maxilla. B: Ossifying fibroma showing cellular fibrous tissue mass infiltrated by woven bone trabeculae. (H\&E X100)

\section{Salivary gland tumors}

Six percent of the studied cases were salivary gland tumors. Two patients $(33.33 \%)$ were males and four patients $(66.67 \%)$ were females. There was no statistically significant difference between the percentages of males and females diagnosed with salivary gland tumors. $(\mathrm{P}>0.05)$

Age groups represented as; group three represented three patients $(50.0 \%)$ and group four represented three patients $(50.0 \%)$. There was no statistically significant difference between the percentages of the age groups diagnosed with salivary gland tumors. $(\mathrm{P}>0.05)$

The anatomical distribution of the studied cases showed that the most common site of occurrence was the parotid gland two cases $(33.32 \%)$, followed by the cheek, mandible, palate and maxilla each represented by one case (16.67\%) from all the studied patients. There was statistically significant difference between the percentages of the anatomical location diagnosed with salivary gland tumors. ( $\mathrm{P}$ $\leq 0.05)$

Six percent of the studied cases were the salivary gland tumors. One case was warthin's tumor which is the benign salivary gland tumor. Five cases were malignant salivary gland tumors which were two cases of myoepithelial carcinoma, two cases of adenocarcinoma and only one case of mucoepidermoid carcinoma. (Figure 6) 




Figure 6: A: clinical view of the patient showing a swelling in the left parotid gland. B: warthin's tumor showing multiple cystic spaces lined by double rows of oncocytes associated with a dense lymphoid stroma. (H\&E X 100)

\section{DISCUSSION}

In the current survey, 100 patients were included and studied through the year 2014 from the Outpatient Clinic of Oral and Maxillofacial Surgery Department, Faculty of Dentistry, Alexandria University. The histopathological study was conducted in the Oral Pathology Department, Faculty of Dentistry, Alexandria University.

The patients' age in the current study ranged between 2 days and 75 years. They were divided into 4 age groups; group one ( 2 days - 15 years), group 2 (16-35 years) which was the most common group, group 3 (36-55 years) and group 4 (56-75 years).

The male to female ratio was $1.04: 1$ that is smaller than several reported literature as that of Gaspar et al. (12) and Busquets et al. (13) who reported ratios of $3: 1$ and $5: 1$, respectively.

In the present study, odontogenic cysts were more common in males than in females, which confirmed conclusions reported in other studies (14-16). The mandible was the most frequently affected anatomical site, which agreed with findings described by Meningaud et al. (17) and Koseoglu et al. (18). Other studies disagree with this prevalence (19). In the present study, radicular cysts accounted for $46.875 \%$ of all cysts and were the most frequent of all lesions in relative terms. This finding is similar to that described by Tay (20), who reported a frequency of $50.7 \%$ and the same as that described by Mosqueda et al. (14) (52\%) where results revealed and Shear (21), (52.3\%).

In the present study, the prevalence among the males $(68.75 \%)$ was higher than the females in the present study, which is in agreement with some studies $(16,19)$.

The greater prevalence in the males was explained by the fact that men customarily have worse oral hygiene habits and are more susceptible to trauma than women (14).

According to the literature, the most affected site is the anterior region of the maxilla $(14,15,19)$. This finding was not corroborated by the present study, which was in agreement with a study by Meningaud et al. (17), who reported that the mandible is the most affected site. The third and fourth decades of life were the most frequent in the present study, which is in agreement with findings described in the literature $(14-16,18,19)$.

Regarding dentigerous cysts, it occupied second place in relative frequency $(18.75 \%)$, which is in agreement with that described in a study carried out in Mexico (14-16). The exception was the study described by Tay (20), in which dentigerous cysts were ranked third place, with a frequency of $15.2 \%$. A greater frequency of dentigerous cysts was found among the male gender $(66.67 \%)$.
This type of cyst was found to occur mainly in the second and third decades of life, which corroborates the findings of previous studies $(14,16)$. Concerning the preferential site of dentigerous cysts, the results of the present study (mandible) differ from those described by Waldron (22), who found the upper third molars to be the most prevalent site.

In present study $25 \%$ of the tumors were benign nonodontogenic, occurring more commonly in age group 4 (56$75 y$ ). From benign non-odontogenic tumors, mesenchymal tumors were found more frequently. Many authors have confirmed this finding (23-25).

Odontogenic tumors were found more commonly in age group 2 (16-35y). Most of the studies have supported this result $(23,24)$. Keratocystic odontogenic tumor has been noted as the most frequent odontogenic tumor in the present study. In other studies, that have considered ameloblastoma has been the most common $(25,26)$. In the current study, the majority of ameloblastomas were solid type.

The majority of salivary gland tumors were located in the parotid gland $(33.33 \%)$ and this is in agreement with some authors who registered involvement of the parotid gland in salivary gland tumors, showing only $36.6 \%$. According to other reports, the palate was the most frequent site of the minor salivary glands tumors (27-29).

In this study, epidemiological data was compared with other worldwide series regarding the distribution of salivary gland tumors. Females and the parotid gland were the most affected and myoepithelial carcinoma was the most frequent lesion, followed by adenocarcinoma, mucoepidermoid carcinoma and warthin's tumor.

Salivary gland tumors more often affected females, with an overall male: female ratio of 1:2. Similarly, other studies describe a male: female ratio varying from $1: 1.2$ to $1: 3$ (27); however, some authors reported predominance for males with a male: female ratio of 1.4:1 (28). Females were predominantly affected in almost all histologic types, except warthin's tumor.

In the current study, malignant tumors represented $83.33 \%$ of all salivary gland tumors. The most frequent in this study was myoepithelial carcinoma. This is in contrast with other studies that reported mucoepidermoid carcinoma to be the most common malignant tumor $(28,30)$. Adenocarcinoma was the second most common malignant type $33.33 \%$ of all tumors, as described by Ansari et al. (30). However, in another study, this tumor was the third most frequent (29).

\section{CONCLUSIONS}

Cysts are most common oral swelling, followed by odontogenic tumors. The treatment modalities were: marsupialization, enucleation, resection, segmental mandibulectomy or hemimandibulectomy. Following surgical removal of jaw swelling, the entire surgical specimen and not only a biopsy specimen, should be examined histopathologically to confirm the clinical and radiographic diagnosis, and to help in the choice of the treatment modality that will be performed.

\section{CONFLICT OF INTEREST}

The authors declare that they have no conflicts of interest.

\section{REFERENCES}

1. Ridge JA, Glisson BS, Horwitz EM, Meyers MO. Head and neck tumors. In: Richard P, Kevin AC, Lawrence 
DW, William JH. $11^{\text {th }}$ ed. Cancer Management: A Multidisciplinary Approach book. United Kingdom: Cmp United Business Media, 2008. 39-89.

2. Thomas G, Hashibe M, Jacob BJ, Ramadas K, Mathew B, Sankaranarayanan R, et al. Risk for Factors Multiple Oral Premalignant Lesions. Int J Cancer 2003; 107: 285-91.

3. Ravi M, Mamata S, Kishore GR, Manish S, Kapoor AK. Trends of prevalence and pathological spectrum of head and neck cancers in North India. Indian J Cancer 2005; 42: 8993.

4. Manor E, Kachko L, Puterman MB, Szabo G, Bodner L. Cystic Lesions of the Jaws - A Clinicopathological Study of 322 Cases and Review of the Literature. Int J Med Sci 2012; 9: 20-6.

5. Ghosh PK. Odontogenic and Non-Odontogenic Tumors. Synopsis of Oral and Maxillofacial Surgery book. $1^{\text {st }}$ ed. India: Jaypee Brothers Medical Publishers, 2006. 96-107.

6. Pogrel MA, Schmidt BL, Robertson CG. Clinical Pathology: Odontogenic and Nonodontogenic Tumors of the Jaws. In: Part II oncology book. 2006. 490-534.

7. College of American Pathologists. National Cancer Institute, American Head and Neck Society. squamous cell carcinoma of the lip or oral cavity. 2011.

8. Rousseau A, Badoual C. Atlas of Head and Neck Pathology, Squamous Cell Carcinoma. Genet Cytogenetics Oncol Haematol 2011.

9. Flávia ADO, Eliza CBD, Cláudia TT, Aline AM, Érica Carvalho DA, Rita DCA, et al. Salivary Gland Tumor: A Review of 599 Cases in a Brazilian Population. Head Neck Pathol 2009; 3: 271-5.

10. Riachi F, Tabarani C. Effective Management of Large Radicular Cysts Using Surgical Enucleation vs. Marsupialization. IAJD 2009; 1: 44-51.

11. Caruana SM, Close LG, Rahmati R. Head and Neck Masses. Columbia: Columbia Presbylerian Medical Center, Dep Otolaryngol, Div Head Neck Surg, 2007.

12. Gaspar C, Zapater E, Chust M, et al. Experience in the treatment of 98 carcinomas of the nasopharynx. Long-term follow-up and analysis of prognostic factors. Acta Otorrinolaringol Esp 2000; 51:691-6.

13. Busquets J, Garcia H, Trindad-Pinedo J, et al. Clinicopathologic characteristics of head and neck squamous cell carcinoma in Puerto Ricans. PR Health Sci J 2003; 22:254-64.

14. Mosqueda-Taylor A, Irigoyen-Camacho ME, Diaz- Franco MA, Torres-Tejero MA. Odontogenic cysts. Analysis of 856 cases. Med Oral 2002; 7: 89-96.

15. Ochsenius G, Escobar E, Godoy L, Penãfiel C. Odontogenic cysts: analysis of 2,944 cases in Chile. Med Oral Patol Oral Cir Bucal 2007; 12: E85-91.

16. Ledesma-Montes C, Hernández-Guerrero JC, Garcés-Ortíz M. Clinico-pathologic study of odontogenic cysts in a Mexican sample population. Arch Med Res 2000; 31: 373 6.

17. Meningaud JP, Oprean N, Pitak-Arnnop P, Bertrand JC. Odontogenic cysts: a clinical study of 695 cases. J Oral Sci 2006; 48: 59-62.

18. Koseoglu BG, Atalay B, Erdem MA. Odontogenic cysts: a clinical study of 90 cases. J Oral Sci 2004; 46: 253-7.

19. Bataineh AB, Rawashdeh MA, Al Qudah MA. The prevalence of inflammatory and developmental odontogenic cysts in a Jordanian population: a clinicopathologic study. Quintessence Int 2004; 35: 815-9.

20. Tay AB. A 5-year survey of oral biopsies in an oral surgical unit in Singapore: 1993-1997. Ann Acad Med Singapore 1999; 28: 665-71.

21. Shear M. Cysts of the oral regions. $3^{\text {rd }}$ ed. London: Wright, Oxford, 1992. 75-98.

22. Waldron CA. Odontogenic cysts and tumors. In: Neville B, Damm D, Allen C, Bouquot J (eds). Oral \& maxillofacial pathology, Philadelphia: WB Saunders, 1995. 481-524.

23. Elarbi M, El-Gehani R, Subhashraj K, Orafi M. Orofacial tumors in Libyan children and adolescents. A descriptive study of 213 cases. Int J Pediatr Otorhinolaryngol 2009; 73: 237-42.

24. Tanaka N, Murata A, Yamaguchi A, Kohama G. Clinical features and management of oral and maxillofacial tumors in children. Oral Surg Oral Med Oral Pathol Oral Radiol Endod 1999; 88: 11-5.

25. Ulmasky M, Lustmann J, Balkin N. Tumors and tumor-like lesions of oral cavity and related structures in Israeli children. Int J Oral Maxillofac Surg 1999; 28: 291-4.

26. Adebayo ET, Ajike SO, Adekeye EO. Tumors and tumorlike lesions of the oral and perioral structures of Nigerian children. Int J Oral Maxillofac Surg 2001; 30: 205-8.

27. Al-Khateeb TH, Ababneh KT. Salivary tumors in north Jordanians: a descriptive study. Oral Surg Oral Med Oral Pathol Oral Radiol Endod 2007; 103: e53-e9.

28. Otoh EC, Johnson NW, Olasoji H, Danfillo IS, Adeleke OA. Salivary gland neoplasms in Maiduguri, north-eastern Nigeria. Oral Dis 2005; 11: 386-91.

29. Kayembe MK, Kalengayi MM. Salivary gland tumors in Congo (Zaire). Odontostomatol Trop 2002; 25: 19-22.

30. Ansari MH. Salivary gland tumors in an Iranian population: a retrospective study of 130 cases. J Oral Maxillofac Surg 2007; 65: 2187-94. 